\title{
Foramen esternal vs orificio por proyectil de arma de fuego.
}

Sternal foramen vs orifice of a gunshot wound.

F. Rodes Lloret

Cuad Med Forense 2004;35:71-74

Durante el estudio antropológico de los restos óseos de un varón de 3 I años se encontraron en el esternón dos orificios (Fig. I y 2). Uno de ellos, localizado a nivel de la $2^{\text {a }}$ esternebra, presentaba bordes irregulares y líneas de fractura (Fig. 3). Se trataba de un orificio por proyectil de arma de fuego. El otro, localizado a nivel de la $3^{a}$ esternebra se corresponde a un foramen esternal (Fig. 4). Dicho orificio presenta las siguientes características: único, de bordes lisos y redondeados, localizado en la línea media, a nivel de la $3^{a}$ esternebra, y sin líneas de fractura.

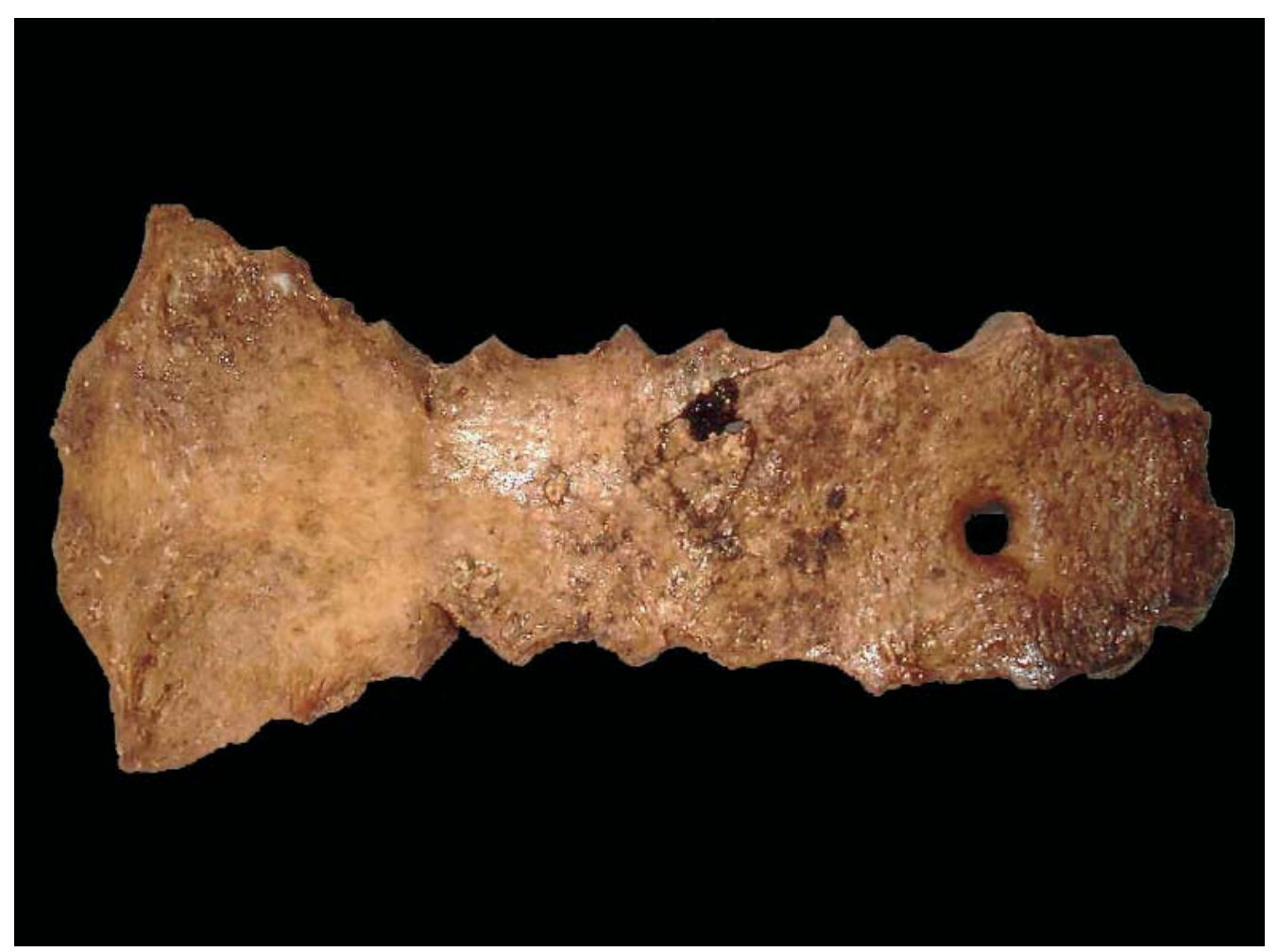

Figura 1.- Esternón con los dos orificios. 


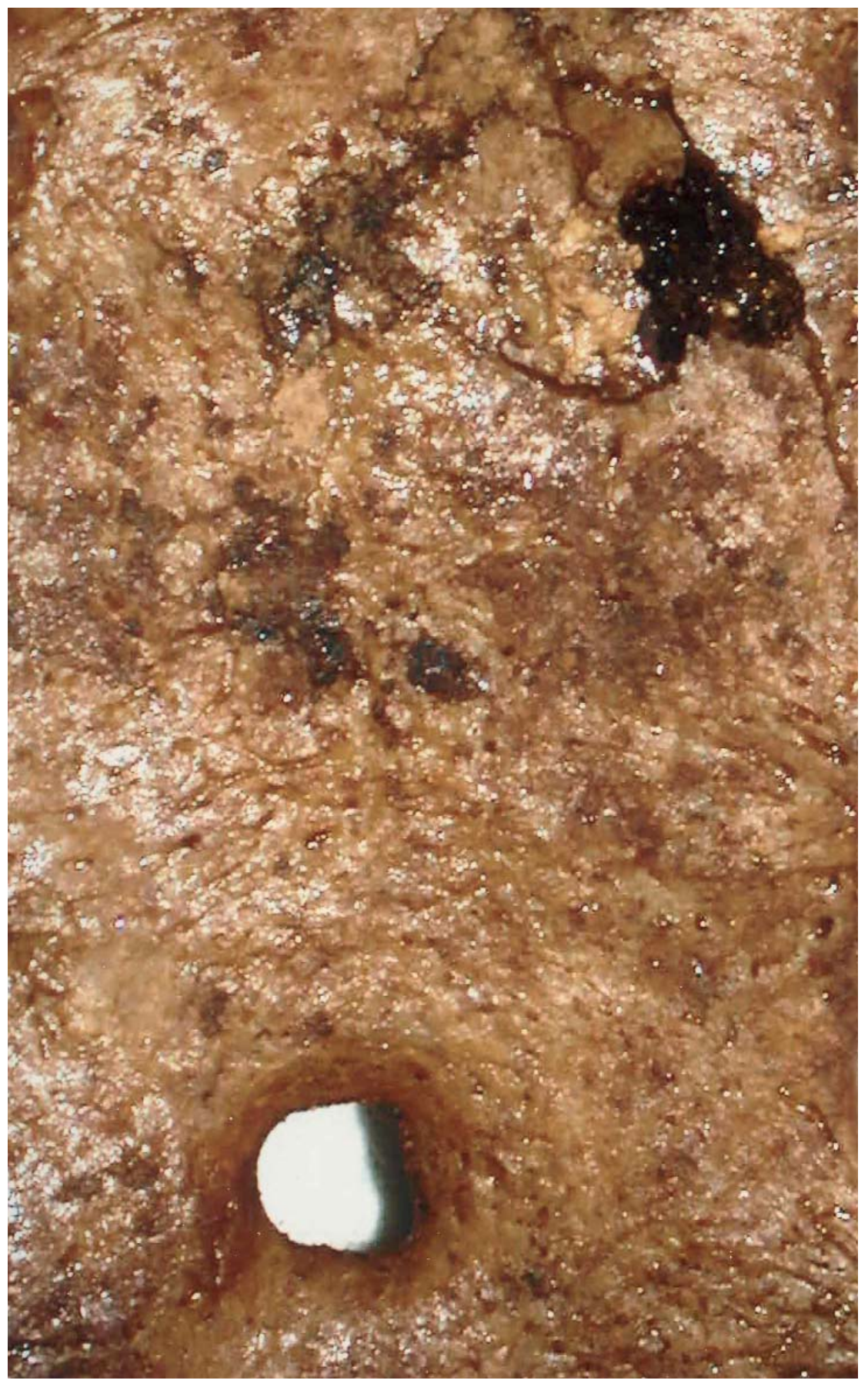

Figura 2.- Detalle de ambos orificios. 


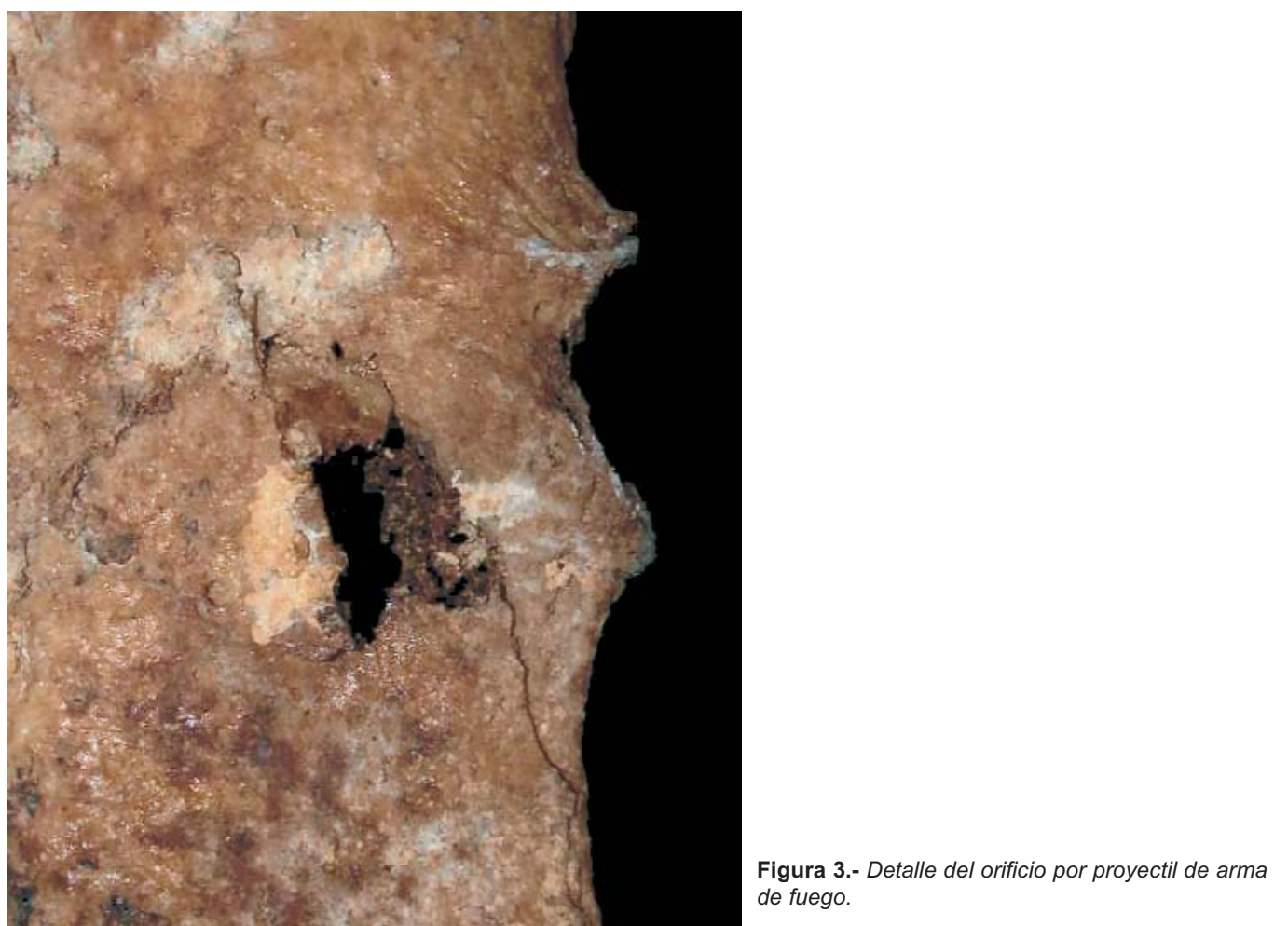

de fuego.

Figura 4.- Detalle del foramen oval.

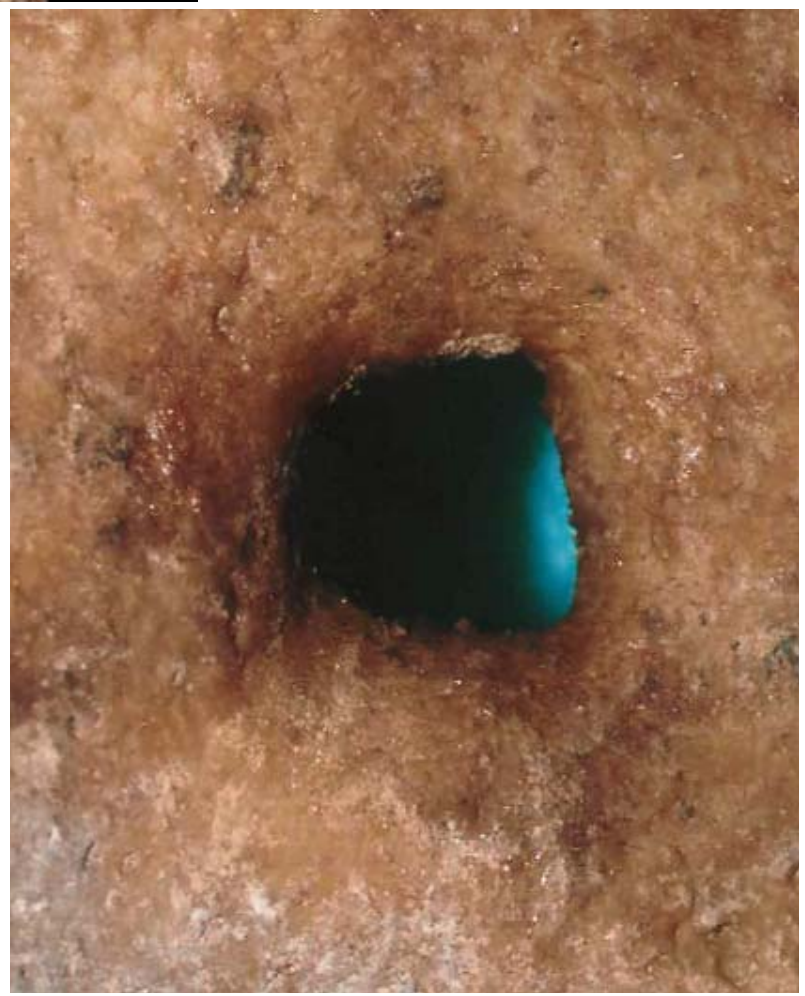

